\title{
Time-dependent modeling of the solar modulation of cosmic rays
}

\section{N.E. Engelbrecht*}

South African National Space Agency (SANSA)

E-mail: n.eugene.engelbrechtegmail.com

\section{Potgieter}

North-West University (Potchefstroom campus)

E-mail: Marius.Potgieterenwu.ac.za

\section{$X$. Luo}

North-West University (Potchefstroom campus)

E-mail: Luoxi1000egmail.com

\section{R.D. Strauss}

North-West University (Potchefstroom campus)

E-mail: dutoit.straussegmail.com

\begin{abstract}
The stochastic approach to solving the Parker transport equation has relatively recently become a popular means of furthering the numerical study of cosmic ray modulation. This is in part due to the fact that this approach allows for three-dimensional, time-dependent simulations over a range of energies that could not be performed using earlier finite difference techniques. We present here preliminary results from one such study, showing galactic cosmic ray proton intensities computed using a time-dependent stochastic modulation code, employing observationally motivated solar cycle-dependent expressions for the heliospheric magnetic field, tilt angle, and solar wind speed. Qualitative comparisons with spacecraft observations of cosmic ray intensities will also be made.
\end{abstract}

The 34th International Cosmic Ray Conference,

30 July- 6 August, 2015

The Hague, The Netherlands

\footnotetext{
* Speaker.
} 